\title{
Fenologia de espécies do dossel e do sub-bosque de duas Florestas de Restinga na Ilha do Mel, sul do Brasil
}

\author{
MÁRCIA C.M. MARQUES ${ }^{1,3}$ e PAULO EUGÊNIO A.M. OLIVEIRA²
}

(recebido: 7 de agosto de 2002; aceito: 12 de agosto de 2004)

\begin{abstract}
Phenology of canopy and understory species of two Coastal Plain Forests in Southern Brazil). The Atlantic Rain Forest is widely distributed in Brazilian coast, and due to environmental differences among sites, ecological processes in plant communities may be different. To test for local and regional effects on plant phenology, we studied during two years the phenology of 55 canopy and understory plant species in two Coastal Plain Forests (Flooded and Unflooded) in Ilha do Mel island one of the most Southern Atlantic Forest area. The study site is one of more southern Atlantic Forest and regional rainfall in the wetter season (September to May) is similar to that of the less wet season (June to August). Flooded and Unflooded Forests showed very similar phenological patterns in which leaf fall (October to December), flushing (December to January), flowering (December to January), and fruiting (March to April) occurred during the wetter season. Almost all phases were correlated with daylength and temperature. Canopy and understory species did not share phenological patterns, and canopy species had a synchronous pattern. The phenology of Coastal Plain Forests of Ilha do Mel is very similar to other ecosystems of Atlantic Rain Forest in Brazil, reflecting floristic links among these areas.
\end{abstract}

Key words - Atlantic Rain Forest, daylength, flowering, fruiting, leaf-flushing

RESUMO - (Fenologia de espécies do dossel e do sub-bosque de duas Florestas de Restinga na Ilha do Mel, sul do Brasil). Devido à ampla distribuição geográfica, a Floresta Atlântica e os ecossistemas associados estão sujeitos a condicionantes ambientais que variam de acordo com a latitude e que devem influenciar nos processos dinâmicos das comunidades. Para avaliar se a fenologia de florestas da região atlântica pode ser determinada por tais variações, plantas do dossel e do sub-bosque (total 55 espécies) de duas Florestas de Restinga (Floresta não inundável e Floresta inundável) foram acompanhadas por dois anos na Ilha do Mel, localizada em região meridional da distribuição da Floresta Atlântica e com pouca diferença climática entre o período superúmido (setembro a maio) e úmido (junho a agosto). Apesar das diferenças florísticas e estruturais, as duas florestas apresentaram padrões semelhantes, com pico de queda de folhas (outubro a dezembro), brotação (dezembro a janeiro), floração (dezembro a janeiro) e frutificação (março a abril) ocorrendo sucessivamente ao longo da estação superúmida, o que esteve correlacionado principalmente com as variações do comprimento do dia e da temperatura. Dossel e sub-bosque apresentaram padrões fenológicos distintos, sendo que no primeiro houve maior sincronia interespecífica. Os resultados mostraram que mesmo localizadas na situação marginal de distribuição do clima tropical, as Florestas de Restinga da Ilha do Mel apresentam semelhanças fenológicas com outros ecossistemas da região atlântica, o que deve refletir a similaridade florística entre estas áreas.

Palavras-chave - brotação, comprimento do dia, floração, Floresta Atlântica, frutificação

\section{Introdução}

Entre os diferentes fatores que condicionam os padrões fenológicos das espécies vegetais (ver Van Schaik et al. 1993), a sazonalidade climática provavelmente seja o mais importante (Arroyo et al. 1981, Wright \& Van Schaik 1994, Rivera \& Borchert 2001). Em ambientes tropicais onde a sazonalidade na

\footnotetext{
1. Universidade Federal do Paraná, SCB, Departamento de Botânica, Caixa Postal 19031, 81531-970 Curitiba, PR, Brasil.

2. Universidade Federal de Uberlândia, IB, Departamento de Biociências, Caixa Postal 593, 38400-902 Uberlândia, MG, Brasil.

3._Autor para correspondência: mmarques@ufpr.br
}

precipitação é pronunciada, a época seca comumente determina a fenologia, limitando o crescimento e reprodução das plantas neste período (Reich \& Borchert 1984, Morellato et al. 1989). No entanto, mesmo em regiões pouco sazonais, as plantas ainda exibem periodicidade em muitos eventos fenológicos (Hilty 1980, Longman \& Jeník 1987, Talora \& Morellato 2000), o que sugere que mais do que a precipitação, as variações no comprimento do dia e/ou temperatura durante o ano determinam a fenologia nestes locais (Morellato et al. 2000, Marques et al. 2004).

Seguindo o gradiente latitudinal, a relação da fenologia de plantas tropicais com o fotoperíodo tende a aumentar à medida em que afasta-se da linha equatorial (Alvim 1964, Ter Steege \& Persuade 1991). Em ecossistemas localizados na região ecotonal entre a 
zona tropical e a zona subtropical, esta relação entre fenologia e comprimento do dia (o qual está intimamente relacionado com a temperatura) é forte (Marques et al. 2004). Portanto, em ecossistemas cuja distribuição geográfica ultrapassa os limites das regiões climáticas, vários padrões fenológicos podem ser esperados.

Além do clima regional, as plantas estão sujeitas às variações ambientais locais que podem ter influência nos padrões fenológicos. Por exemplo, em estudo realizado em florestas inundáveis amazônicas, Kubitzki \& Ziburski (1994) verificaram que a época de frutificação estava relacionada com o ritmo de inundações. Também Callado et al. (2001) observaram que algumas espécies da Floresta Atlântica apresentavam periodicidade na fenologia e na formação de anéis de crescimento em função de variações no regime hídrico local. Então, espera-se que plantas sujeitas a diferentes condições hídricas do solo podem apresentar distinção em seus padrões fenológicos.

Em uma comunidade vegetal, as espécies diferem em suas habilidades em captar e armazenar recursos. Espécies arbóreas, que ocupam os estratos superiores de uma floresta, comparando-se com as arbustivas e herbáceas dos estratos inferiores, apresentam, em geral, sistemas radiciais mais profundos e estão sujeitas a uma maior insolação, o que influencia os seus padrões fenológicos (Croat 1975, Opler et al. 1980, Marques et al. 2004). Paralelamente a isto, as atividades de polinizadores, dispersores, herbívoros e patógenos que interagem com a comunidade vegetal são fortemente influenciadas pela fenologia (Smithe 1970, Frankie et al. 1974). Portanto, estudar a diferenciação fenológica entre as sinúsias de uma fitocenose é um importante passo para a compreensão da exploração de nichos pelas populações vegetais e animais.

A Floresta Atlântica e os ecossistemas a ela associados distribuem-se por quase todo o litoral brasileiro e são representados por diferentes unidades fitoecológicas que guardam entre si uma forte relação (Fernandes 2000). Embora a grande amplitude de distribuição geográfica destas formações, que implica na ocorrência em locais de climas tipicamente tropical a subtropical, as características fisionômicas, florísticas e estruturais se mantêm (Negrelle 2002). Porém, como fenologia é fortemente determinada pelo clima, ecossistemas da Floresta Atlântica localizados em diferentes latitudes podem apresentar padrões fenológicos também distintos (Morellato et al. 2000). Estudos abordando a fenologia de comunidades nestes locais foram feitas por Jackson 1978, Delitti 1987, Costa et al. 1997, Talora \& Morellato 2000 e Morellato et al.
2000, todos no litoral sudeste, mas pouco se conhece sobre a fenologia da Floresta Atlântica localizada mais ao sul do Brasil.

Entre as formações vegetacionais da região atlântica localizadas no Estado do Paraná, as Florestas de Restinga são caracterizadas por distribuírem-se ao longo dos cordões litorâneos, formados por sedimentos marinhos de origem Quaternária ao longo da planície costeira (Silva et al. 1994). A localização das florestas sobre ou nas depressões de tais cordões define diferentes tipos florestais, influenciados, principalmente, pela profundidade do lençol freático e, conseqüentemente, pela possibilidade de inundação (Britez et al. 1997).

No presente estudo acompanhou-se, por dois anos, a fenologia de plantas de diferentes estratos de duas Florestas de Restinga (Floresta não inundável e Floresta inundável), localizadas na Planície Litorânea da Ilha do Mel, PR. O trabalho teve três objetivos principais: 1) Verificar se estas florestas, situadas em região transicional dos climas tropical e sub-tropical, são sazonais e se comportam como outras florestas da região atlântica. Para tanto serão descritos os eventos fenológicos (mudança foliar, floração e frutificação) das duas florestas, verificada a relação dos mesmos com o clima (comprimento do dia, temperatura e precipitação) regional e feita a comparação com outros estudos. 2) Investigar se a fenologia de Florestas de Restinga pode estar relacionada com a disponibilidade de água no solo, um importante fator ambiental local. Para tanto serão comparados os padrões fenológicos da Floresta não inundável e da Floresta inundável, as quais estão sujeitas a diferentes condições hídricas do solo. 3) Comparar a fenologia do dossel e do sub-bosque, para verificar a existência de diferenciação fenológica entre sinúsias.

\section{Material e métodos}

Área de estudo - A Ilha do Mel está localizada na região central do litoral paranaense, no município de Paranaguá, entre as coordenadas $25^{\circ} 29^{\prime}-25^{\circ} 34^{\prime} 32^{\prime \prime} \mathrm{S}$ e $48^{\circ} 17^{\prime} 15^{\prime \prime}$ $48^{\circ} 23^{\prime} 16^{\prime \prime} \mathrm{W}$ e possui uma área aproximada de 2.760 ha. A maior parte da ilha é constituída por uma planície litorânea sobre a qual desenvolve-se um mosaico vegetacional onde destacam-se dois tipos de Floresta de Restinga (senso Silva et al. 1994), as Florestas não inundáveis (FNI) e as Florestas inundáveis (FI), ambas bastante representativas da região (Silva 1998). Estas florestas diferem entre si basicamente pela posição relativa nos cordões litorâneos, o que influencia na saturação de água no solo (Britez 1994). A FNI ocorre nas partes altas dos cordões, em locais de drenagem rápida, onde o lençol freático está, em média (dados médios anuais para 
1991-1992), a $104 \mathrm{~cm}$ de profundidade (Britez 1994). A FI acompanha as depressões entre os cordões, onde lençol freático, em média a $49 \mathrm{~cm}$ de profundidade (Britez 1994), aflora no período mais chuvoso do ano (novembro a março). Nesta floresta o terreno apresenta pequenas variações topográficas, estabelecendo no solo uma variedade de situações de maior ou menor saturação hídrica. Estas diferenças de substrato implicam em estrutura e composição florística distintas nas duas florestas (Silva 1998). A FNI apresenta um dossel relativamente baixo (altura de 8-10 m), seguido por sub-bosque iluminado, bem desenvolvido e rico em espécies de bromélias. A FI apresenta um dossel mais alto (altura aproximada de $15 \mathrm{~m}$ ), seguido por um estrato intermediário (altura entre 8-12 m), com a ocorrência basicamente das mesmas espécies do dossel, e um subbosque menos expressivo (Silva 1998). Apesar da diferença em riqueza de espécies entre a FNI (dossel $=33 \mathrm{e}$ sub-bosque $=28$ espécies), e a FI (dossel $=60 \mathrm{e}$ sub-bosque $=19$ espécies de Angiospermas), ambas guardam entre si alguma similaridade florística (coeficiente de similaridade de Sørensen no dossel S = 0,49 e no sub-bosque $\mathrm{S}=0,21$; de acordo com dados de Silva 1998). Ambas estão próximas entre si (aproximadamente $700 \mathrm{~m}$ ) e situadas sobre solo Podzol distrófico A (Britez et al. 1997).

O clima da região de Paranaguá é do tipo Af de Köppen, tropical, superúmido, sem estação seca e isento de geadas. A caracterização climática local foi feita através de climatogramas com dados mensais médios de 46 anos (1948-1993, de acordo com Britez 1994) e de medida astronômica padrão para a latitude (obtida em www.saunalahti.fi/ jjlammi/sun.php3/). Para este período, a temperatura média para a região foi $21^{\circ} \mathrm{C}$ e a precipitação anual $2.218 \mathrm{~mm}$ (Britez 1994), sendo o período de setembro a abril o mais quente e chuvoso e maio a agosto o mais frio e seco (figura 1). Como as diferenças entre as duas épocas são pouco pronunciadas, estas são aqui denominadas, respectivamente, como período superúmido (precipitação sempre superior a $150 \mathrm{~mm}$ e temperatura média ao redor de $22{ }^{\circ} \mathrm{C}$ ) e período úmido (precipitação entre $70-150 \mathrm{~mm}$ e temperatura de aproximadamente $17^{\circ} \mathrm{C}$ ).

Métodos - Foram estudadas espécies amostradas por Silva (1998) em estudos fitossociológicos realizados em duas áreas de $3.000 \mathrm{~m}^{2}$ na Floresta não inundável (FNI) e na Floresta inundável (FI). Em cada floresta este autor amostrou árvores e arvoretas (perímetro da base $>10 \mathrm{~cm}$ ), arbustos e ervas (presentes em parcelas de $1 \mathrm{~m}^{2}$ ) através do método de parcelas. Para o estudo fenológico escolheram-se as espécies que totalizaram $80 \%$ do Valor de Importância (IVI total) do dossel (árvores) e do sub-bosque (arbustos e ervas) de cada área. Devido à representatividade da Família nestes tipos florestais, no segundo ano de observações foram incorporadas todas as demais espécies de Myrtaceae presentes nas áreas. No total foram observadas 29 espécies na FNI e 31 espécies na FI, sendo que cinco eram comuns às duas áreas (tabela 1). Para a maioria das espécies, foram marcados cinco indivíduos para as observações (como sugerido por Fournier \&

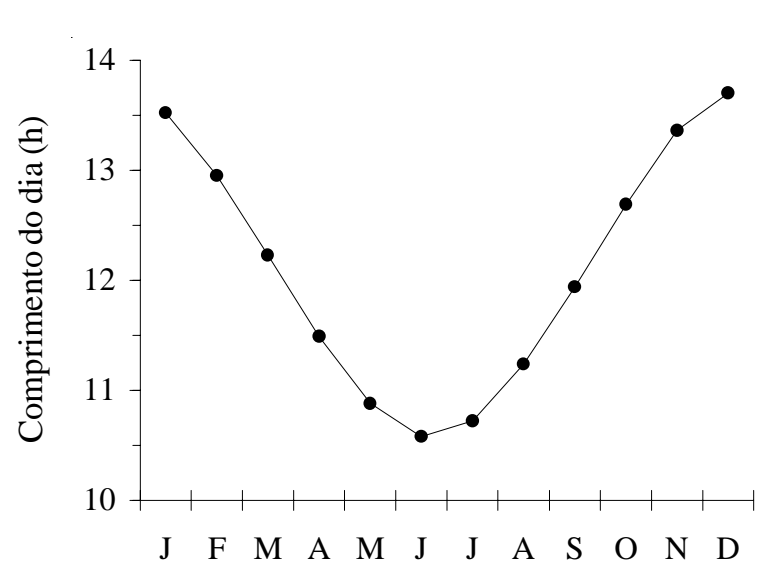

A

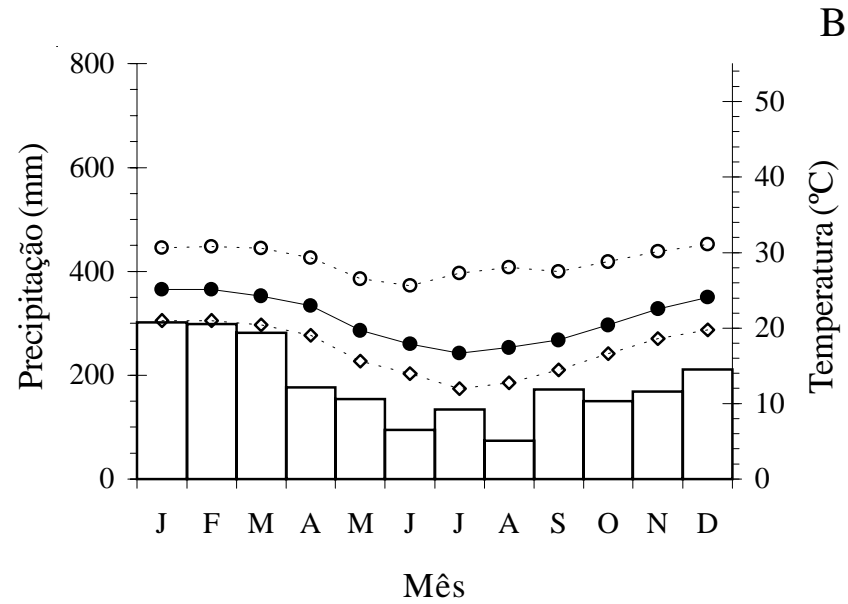

Figura 1. Comprimento do dia (A) e médias de precipitação e temperaturas (média, máxima e mínima) para o período de 1948 - 1993 (B), para a região de Paranaguá, PR. B: $\square=$ Precipitação; $-\bullet-=$ Temp. média; $-\diamond-=$ Temp. mínima;-0- = Temp. máxima.

Figure 1. Daylength (A) and average rainfall and temperature (average, maximum and minimum) along 1948-1993 (B), to Paranaguá, Paraná State. B: $\square=$ Rainfall; $-\bullet-=$ Temp. average $;-\diamond-=$ Temp. minimum; $-\mathrm{O}-=$ Temp. maximum.

Charpantier 1975), mas em alguns casos, devido ao fato das populações serem pequenas, este número foi inferior (tabela 1). As plantas foram observadas de outubro de 1998 a setembro de 2000, a cada 30 dias, a olho nu ou com um binóculo, com relação à presença ou não de mudança foliar (brotação e queda de folhas), floração (botões e flores abertas) e frutificação (frutos imaturos e maduros).

Os padrões fenológicos das comunidades florestais foram descritos através de fenogramas (porcentagem de espécies em uma dada fenofase, por mês), os quais serviram para a comparação com os padrões de outras comunidades já estudadas. Para verificar a relação entre fenologia e as variáveis climáticas (temperaturas, precipitação e comprimento do dia médios mensais) foram utilizadas correlações de Spearman $\left(r_{s}\right)$, de acordo com Zar (1999). Como 


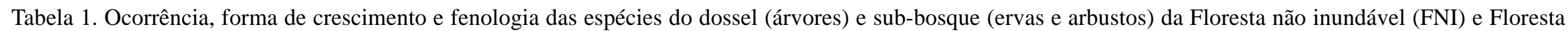
inundável (FI), na Ilha do Mel, PR.

Table 1. Occurrence, life-form, and phenology of dossel species (trees) and understory species (herbs and shrubs) of Unflooded (FNI) and Flooded (FI) Sandy Costal Forests, in Ilha do Mel, Paraná State.

\begin{tabular}{|c|c|c|c|c|c|c|c|c|c|}
\hline \multirow[t]{2}{*}{ Família/Espécie } & \multirow[t]{2}{*}{ Local } & \multirow[t]{2}{*}{$\mathrm{n}$} & \multirow{2}{*}{$\begin{array}{l}\text { Forma de } \\
\text { crescimento }\end{array}$} & \multicolumn{2}{|c|}{ Mudança foliar } & \multicolumn{2}{|c|}{ Floração } & \multicolumn{2}{|c|}{ Frutificação } \\
\hline & & & & Brotação & $\begin{array}{l}\text { Queda de } \\
\text { folhas }\end{array}$ & Botões & Flores & Frutos & Frutos \\
\hline \multicolumn{10}{|l|}{ ANACARDIACEAE } \\
\hline Tapirira guianensis Aubl. & $\begin{array}{l}\text { FNI } \\
\text { FI }\end{array}$ & $\begin{array}{l}5 \\
5\end{array}$ & $\begin{array}{l}\text { árvore } \\
\text { árvore }\end{array}$ & $\begin{array}{l}\text { set-jan } \\
\text { out-dez }\end{array}$ & $\begin{array}{l}\text { contínuo } \\
\text { mai-fev }\end{array}$ & $\begin{array}{l}\text { out-dez } \\
\text { out-jan }\end{array}$ & $\begin{array}{l}\text { out-dez } \\
\text { out-jan }\end{array}$ & $\begin{array}{l}\text { dez-fev } \\
\text { dez-fev }\end{array}$ & $\begin{array}{l}\text { jan-mai } \\
\text { jan-abr }\end{array}$ \\
\hline \multicolumn{10}{|l|}{ ANNONACEAE } \\
\hline $\begin{array}{l}\text { Guatteria australis A. St.-Hil. } \\
\text { ARACEAE }\end{array}$ & FI & 6 & árvore & ago, out-mar & abr-dez & out, dez-mar & jan-mai, out a & ago-nov, jan & mai, dez \\
\hline $\begin{array}{l}\text { Anthurium sp. } \\
\text { ARALIACEAE }\end{array}$ & FNI & 5 & erva & out-nov, fev-mar & ago & - & mar-jun & mai-jul & jun-nov \\
\hline $\begin{array}{l}\text { Didymopanax angustissimum March. } \\
\text { ARECACEAE }\end{array}$ & FI & 3 & árvore & ago-dez & mai-dez & nov-dez & nov-dez & dez-jul & jan-out \\
\hline $\begin{array}{l}\text { Geonoma schottiana Mart. } \\
\text { AQUIFOLIACEAE }\end{array}$ & FI & 5 & arbusto & dez-abr & contínuo & dez-jun & mar-jun & abr-jan & mai-fev \\
\hline $\begin{array}{l}\text { Ilex pseudobuxus Reissek } \\
\text { BROMELIACEAE }\end{array}$ & FNI & 5 & árvore & out-abr & contínuo & out-jan & nov-fev & dez-abr & dez-mai \\
\hline Nidularium innocentii (Mez) Sm. & FNI & 5 & erva & - & - & nov-jul & dez-jul & - & - \\
\hline Vrisea atra $\mathrm{Mez}^{* *}$ & FNI & 5 & erva & mai-jan & jul-set & mai-jun & jul & jul & - \\
\hline Vrisea vagans (L.B. Sm.)** & FNI & 5 & erva & - & - & - & - & - & - \\
\hline \multicolumn{10}{|l|}{ CLUSIACEAE } \\
\hline Calophyllum brasiliense Camb. & $\begin{array}{l}\text { FNI } \\
\text { FI }\end{array}$ & $\begin{array}{l}5 \\
5\end{array}$ & $\begin{array}{l}\text { árvore } \\
\text { árvore }\end{array}$ & $\begin{array}{l}\text { out, dez, fev, jul } \\
\text { ago-fev }\end{array}$ & $\begin{array}{l}\text { abr-dez } \\
\text { mai-nov }\end{array}$ & $\begin{array}{l}\text { abr, dez } \\
\text { out-mar }\end{array}$ & $\begin{array}{l}\text { jan, mai, out, dez } \\
\text { out,dez-mar }\end{array}$ & $\begin{array}{l}\text { jan-fev } \\
\text { fev-abr }\end{array}$ & $\begin{array}{l}\text { jan-jul } \\
\text { mar-set }\end{array}$ \\
\hline Clusia criuva Camb. & FNI & 5 & árvore & nov & contínuo & out-dez & dez, jun, set & contínuo & jan-fev \\
\hline $\begin{array}{l}\text { Garcinia gardneriana (Triana \& Planch.) Zappi } \\
\text { CYPERACEAE }\end{array}$ & i FI & 4 & árvore & dez-jan & - & - & - & jan & fev-mai \\
\hline $\begin{array}{l}\text { Scleria latifolia } \text { Sw. } \\
\text { ERYTHROXYLACEAE }\end{array}$ & FNI & 5 & erva & jul-ago & contínuo & ago & jul-set & jun, ago-out & ago-jan \\
\hline $\begin{array}{l}\text { Erytroxylum amplifolium (Mart.) Schult. } \\
\text { EUPHORBIACEAE }\end{array}$ & FNI & 5 & árvore & dez-fev & contínuo & jul-set & jul-set & set-out,fev & nov, fev \\
\hline Alchornea triplinervia (Spreng.) Müll.Arg. & FI & 6 & árvore & out-mar & abr-dez & out-jan & out-nov, fev & dez-jan, mar & dez-mar \\
\hline Pera glabrata (Schott) Baill. & FI & 4 & árvore & dez & mai-dez & - & - & mai & - \\
\hline LAURACEAE & & & & & & & & & \\
\hline Ocotea pulchella Mart. & $\begin{array}{c}\text { FNI } \\
\text { FI }\end{array}$ & $\begin{array}{l}5 \\
5\end{array}$ & $\begin{array}{l}\text { árvore } \\
\text { árvore }\end{array}$ & $\begin{array}{l}\text { dez-jan } \\
\text { nov-fev }\end{array}$ & $\begin{array}{l}\text { contínuo } \\
\text { mai-dez }\end{array}$ & $\begin{array}{l}\text { dez-fev } \\
\text { jan-mar }\end{array}$ & $\begin{array}{l}\text { dez-mar } \\
\text { jan-mar }\end{array}$ & $\begin{array}{l}\text { out-jun } \\
\text { out-nov }\end{array}$ & $\begin{array}{c}\text { nov-ago } \\
\text { out }\end{array}$ \\
\hline LOGANIACEAE & & & & & & & & & \\
\hline Spigelia dusenii L.B. Sm. ** & FI & 4 & erva & out-jan & - & jan-fev & dez-jan & - & - \\
\hline
\end{tabular}




\begin{tabular}{|c|c|c|c|c|c|c|c|c|c|}
\hline \multirow[t]{2}{*}{ Família/Espécie } & \multirow[t]{2}{*}{ Local } & \multirow[t]{2}{*}{$\mathrm{n}$} & \multirow{2}{*}{$\begin{array}{l}\text { Forma de } \\
\text { crescimento }\end{array}$} & \multicolumn{2}{|c|}{ Mudança foliar } & \multicolumn{2}{|c|}{ Floração } & \multicolumn{2}{|c|}{ Frutificação } \\
\hline & & & & Brotação & $\begin{array}{l}\text { Queda de } \\
\text { folhas }\end{array}$ & Botões & Flores & Frutos & Frutos \\
\hline \multicolumn{10}{|l|}{ MELIACEAE } \\
\hline Guarea macrophylla Vahl & FI & 4 & árvore & out-fev & mai-dez & out-jan & out-jan & dez-jul & mar, mai-set \\
\hline MYRSINACEAE & & & & & & & & & \\
\hline Myrsine venosa (DC.) Mez & FNI & 7 & árvore & nov-mar & contínuo & abr-mai & abr-mai & fev-mai & fev-mai \\
\hline \multicolumn{10}{|l|}{ MYRTACEAE } \\
\hline $\begin{array}{l}\text { Calyptranthes lucida var. polyantha (Berg) } \\
\text { Legrand* }\end{array}$ & FI & 1 & árvore & dez-jan & - & - & - & - & - \\
\hline Calyptranthes rubella (Berg) Legrand* & FNI & 5 & árvore & jan-fev & jun-dez & dez-fev & jan-fev & fev-abr & abr-mai \\
\hline Eugenia stigmatosa DC.* & FI & 3 & árvore & - & jun-jul & ago & set & - & - \\
\hline Eugenia sulcata Spring ex Mart. & FI & 5 & árvore & out-jan & mai-dez & ago-out & out & nov-jan & - \\
\hline Eugenia umbelliflora Berg* & FI & 1 & árvore & dez-jan & nov & - & - & - & - \\
\hline Gomidesia schaueriana Berg & FI & 3 & árvore & out-nov & jul-dez & out, dez-jan & nov-jan & dez-mai & jan-jun \\
\hline Marlierea reitzii Legrand & FI & 6 & árvore & out-mar ji & jun, ago, out-nov & out-dez, abr & nov-dez, abr & dez-mai & jan-ago \\
\hline Marlierea tomentosa Camb. & FI & 5 & árvore & out,jan-fev & - & abr-jun & mai-jun & jul-ago & ago \\
\hline Myrcia bicarinata (Berg) Legrand* & FNI & 2 & árvore & jan-mar & out-dez & out & out & nov-abr & mar-abr \\
\hline Myrcia glabra (Berg) Legrand & FI & 4 & árvore & nov-jan & mai-dez & - & - & - & - \\
\hline \multirow{2}{*}{ Myrcia grandiflora Krug \& Urb.* } & FNI & 1 & árvore & jan & out-dez & set & - & - & - \\
\hline & FI & 5 & árvore & out, dez-jan & mai-set, dez & set & - & - & - \\
\hline Myrcia insularis Gardn. & FI & 5 & árvore & jan & contínuo & - & - & - & dez \\
\hline \multirow{2}{*}{$\begin{array}{l}\text { Myrcia racemosa var. gaudichaudiana (Berg) } \\
\text { Legrand* }\end{array}$} & FNI & 5 & árvore & nov-jan & set,nov-dez & - & - & & - \\
\hline & FI & 5 & árvore & out-mar & mai-nov & dez-fev & fev & fev-jun & fev-jul \\
\hline $\begin{array}{l}\text { Myrcia multiflora var. glaucescens (Berg) } \\
\text { Legrand }\end{array}$ & FNI & 5 & árvore & nov-fev & contínuo & out-jan & out-jan & dez-mar & dez,fev-abr \\
\hline Psidium cattleianum Sabine & FNI & 5 & árvore & out-fev, mai-jun & n contínuo & dez, mar & fev, abr, dez & jan-mar & mar-abr \\
\hline Siphoneugena guilfoyleiana C. Proença* & FNI & 1 & árvore & dez-mar & dez-jan, abr-mai & - & - & - & - \\
\hline \multicolumn{10}{|l|}{ NYCTAGINACEAE } \\
\hline Guapira opposita (Vell.) Reitz & $\mathrm{FNI}$ & 5 & árvore & out-jan & jun-dez, mar & nov-jan & nov-fev & jan-fev & - \\
\hline \multicolumn{10}{|l|}{ PIPERACEAE } \\
\hline $\begin{array}{l}\text { Peperomia urocarpa Fisch. \& Mey. } \\
\text { POACEAE }\end{array}$ & FI & POACEAE & erva & - & ago & - & - & - & - \\
\hline Poaceae $1 * *$ & FNI & 5 & erva & - & contínuo & - & - & - & - \\
\hline \multicolumn{10}{|l|}{ RUBIACEAE } \\
\hline Alibertia concolor (Cham.) K.Schum. & FI & 4 & arbusto & out-fev & dez & dez-mar & jan-fev & mar-jul & mar-jul \\
\hline Amaioua guianensis Aubl. & FI & 5 & árvore & out-abr & mar-dez & nov-jan & dez-jan & jan-fev, mai & mar-mai \\
\hline Coccocypselum guianense (Aubl.) K. Schum. & FNI & 4 & erva & nov & abr-set & out-mai & out-mai & nov-jul & mar-ago, nov \\
\hline Faramea marginata Cham. & FI & 5 & árvore & out-jan & set-out & nov-jan & dez-fev & jan-ago & fev-set \\
\hline Psychotria barbiflora DC. & $\mathrm{FNI}$ & 5 & arbusto & mai-jul, out-jan & mar-nov & nov-dez,mar & dez-jan, abr & jan-jun & mar-abr \\
\hline Rudgea villiflora K.Schum. ex Stand. & FI & 5 & arbusto & set-mai & jul-set & out & out-dez & nov-abr & jan-abr \\
\hline THEACEAE & & & & & & & & & \\
\hline Ternstroemia brasiliensis Camb. & $\mathrm{FNI}$ & 5 & árvore & set-jan & contínuo & out-jan & nov-abr & jan-ago & jan-mai \\
\hline
\end{tabular}

* espécies adicionadas no segundo ano de observações; ** espécies com dispersão não zoocórica (segundo Marques 2002) 
as plantas podem apresentar uma resposta fenológica atrasada a um dado estímulo ambiental (Marques et al. 2004), também foi verificada a correlação entre a fenologia e as variáveis climáticas de um a quatro meses anteriores às observações (ver Marques et al. 2004).

Para comparar os padrões fenológicos entre as florestas foram realizadas correlações de Spearman (Zar 1999) utilizando-se o número de espécies em uma determinada fenofase, por mês. Espera-se que, se as condições locais de cada floresta não influenciam a fenologia, as duas florestas devem apresentar o mesmo padrão fenológico e serem fortemente correlacionadas. Por outro lado, se as características locais influenciam a fenologia, os padrões devem ser distintos e as florestas devem ser fracamente ou não correlacionadas. Seguindo esta mesma idéia, dentro de uma mesma floresta este teste também foi utilizado para comparar os padrões fenológicos entre os dois anos de estudo e entre diferentes estratos (dossel e sub-bosque). Em todos os casos $\mathrm{N}=24$, exceto na correlação entre os anos $(\mathrm{N}=12)$.

\section{Resultados}

Padrão fenológico geral e clima - As fenofases mudança foliar, floração e frutificação ocorreram sucessivamente ao longo do ano (figura 2) e não transcorreram da mesma maneira para todas as espécies (tabela 1). Na Floresta não inundável (FNI) e na Floresta inundável (FI) nas árvores do dossel a produção de folhas novas ocorreu principalmente no período de outubro a março, fora do qual poucas espécies brotaram (figuras $2 \mathrm{a}$ e 2b). A queda de folhas foi, para $30 \%$ das espécies, um evento contínuo, mas observou-se um incremento no número de árvores perdendo folhas a partir de maio-junho, com um máximo em outubro-dezembro. Nenhuma das espécies observadas é decídua. No sub-bosque das duas florestas a brotação e a queda de folhas ocorreram quase ininterruptamente durante todo o ano (figuras $2 \mathrm{a}$ e $2 \mathrm{~b}$ ). Botões florais e flores ocorreram simultaneamente na maior parte das espécies e sucederam o início da brotação, principalmente nos meses de novembro e dezembro (figuras $2 \mathrm{c}$ e $2 \mathrm{~d}$ ). Algumas árvores floresceram totalmente fora do período de pico, como é o caso de Erythroxylum amplifolium e Myrsine venosa na FNI e Eugenia stigmatosa e Marlierea tomentosa na FI (tabela 1). No sub-bosque não houve um pico aparente na floração. Frutos imaturos apareceram logo após a floração, na maioria das espécies do dossel, com um pico em janeiro e amadureceram nos meses subseqüentes (tempo médio de maturação dos frutos = 2 meses, mínimo 1 e máximo 12 meses), com pico entre março e maio; no sub-bosque não foi possível identificar nenhum pico (figuras $2 \mathrm{e}$ e $2 \mathrm{f}$ ).
Os padrões fenológicos das comunidades não seguiram a mesma tendência nos dois anos de observação (figura 2). Na FNI e FI, árvores apresentaram semelhança entre anos nas fases brotação (respectivamente $r_{s}=0,81$ e $r_{s}=0,95, \mathrm{p}<0,05$ ), botões florais $\left(r_{s}=0,59\right.$ e $\left.r_{s}=0,74, \mathrm{p}<0,05\right)$, frutos imaturos $\left(r_{s}=0,77\right.$ e $\left.r_{s}=0,81, \mathrm{p}<0,05\right)$ e frutos maduros $\left(r_{s}=0,72\right.$ $\left.\mathrm{e} r_{s}=0,87, \mathrm{p}<0,05\right)$. A queda de folhas repetiu o mesmo padrão nos dois anos somente na FNI $\left(r_{s}=0,6, \mathrm{p}<0,05\right)$ e flores abertas na FI $\left(r_{s}=0,62, \mathrm{p}<0,05\right)$. Arbustos e ervas do sub-bosque foram similares apenas na brotação da FI $\left(r_{s}=0,58, \mathrm{p}<0,05\right)$.

As temperaturas médias, máximas e mínimas mostraram uma mesma tendência nas correlações e, portanto, foram apresentados apenas os dados relativos à temperatura média. De uma forma geral, as fenofases relacionaram-se com o clima de uma mesma maneira nas duas florestas e estas correlações foram significativas e maiores para o comprimento do dia e temperatura e significativas e menores (ou não significativas) para a precipitação (tabela 2). Na maioria dos casos as fenofases correlacionaram-se com o clima de meses anteriores (médias de atraso variando de 1,6 a 2 meses) às observações (tabela 2). Em todas as fenofases o dossel apresentou correlações maiores com as variáveis climáticas que o sub-bosque (exceto queda de folhas na FNI). De maneira geral, brotação, botões florais e flores apresentaram correlação positiva e significativa com o comprimento do dia do período de observação e negativa com temperatura de quatro meses antes. Queda de folhas foi inversamente correlacionada com todas as variáveis, com 0 a 3 meses de deslocamento (tabela 2). No dossel, frutos imaturos e maduros apresentaram correlações positivas significativas com todas as variáveis, com um atraso de um a quatro meses; no sub-bosque as correlações destas fenofases foram baixas ou não significativas (tabela 2). Padrões entre florestas - As árvores do dossel da FNI e da FI apresentaram a mesma tendência no padrão de brotação $\left(r_{s}=0,83, \mathrm{p}<0,01\right)$ e queda de folhas $\left(r_{s}=0,53\right.$, $\mathrm{p}=0,01)$; no sub-bosque, os padrões de mudança foliar foram distintos $\left(r_{s}<0,36, \mathrm{p}>0,05\right)$. A presença de botões florais $\left(r_{s}=0,72, \mathrm{p}<0,01\right)$ e flores $\left(r_{s}=0,78, \mathrm{p}<0,01\right)$ seguiu a mesma tendência no dossel das duas florestas; no sub-bosque não houve relação na floração das duas florestas $\left(r_{s}<0,30, \mathrm{p}>0,10\right)$. A frutificação do dossel das duas florestas manteve relação (frutos imaturos $r_{s}=0,80$; frutos maduros $\left.r_{s}=0,62, \mathrm{p}<0,01\right)$, mas no sub-bosque este fato não se repetiu $\left(r_{s}=-0,03, \mathrm{p}>0,1\right)$. Padrões das sinúsias - Os padrões fenológicos nem sempre se repetiram entre os diferentes estratos 
Floresta não inundável

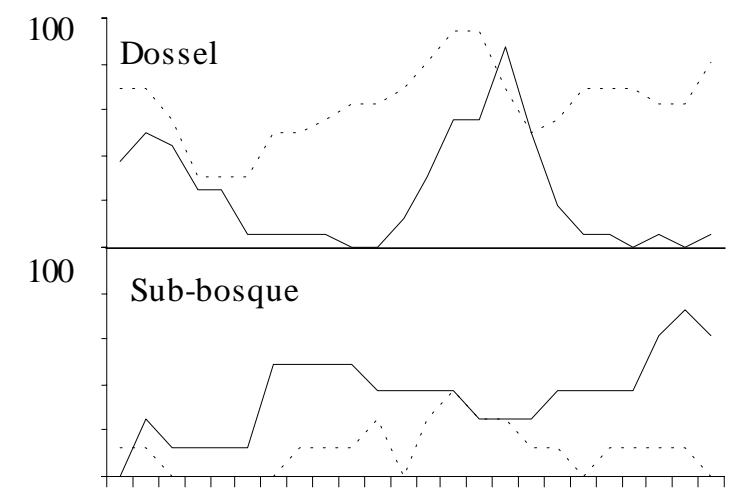

$\begin{array}{llllllllllll}\text { O } & \text { D } & \text { F } & \text { A } & \text { J } & \text { A } & \text { O } & \text { D } & \text { F } & \text { A } & \text { J } & \text { A }\end{array}$

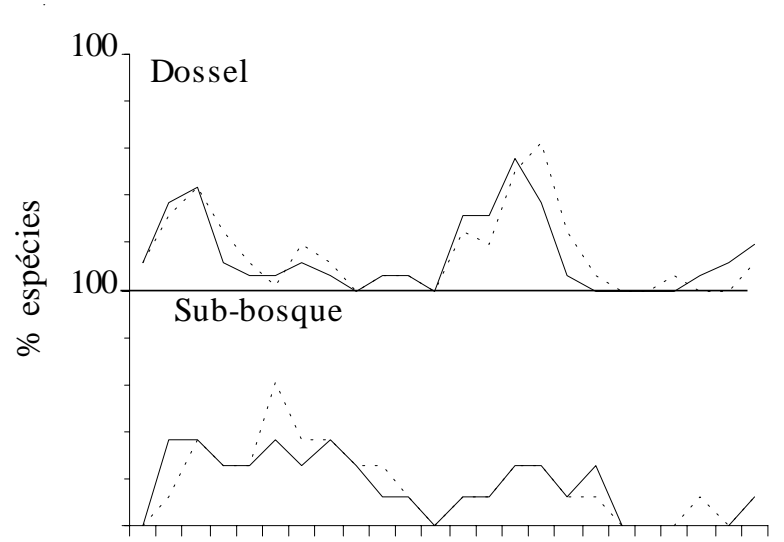

$\begin{array}{llllllllllll}\text { O } & \text { D } & \text { F } & \text { A } & \text { J } & \text { A } & \text { O } & \text { D } & \text { F } & \text { A } & \text { J } & \text { A }\end{array}$

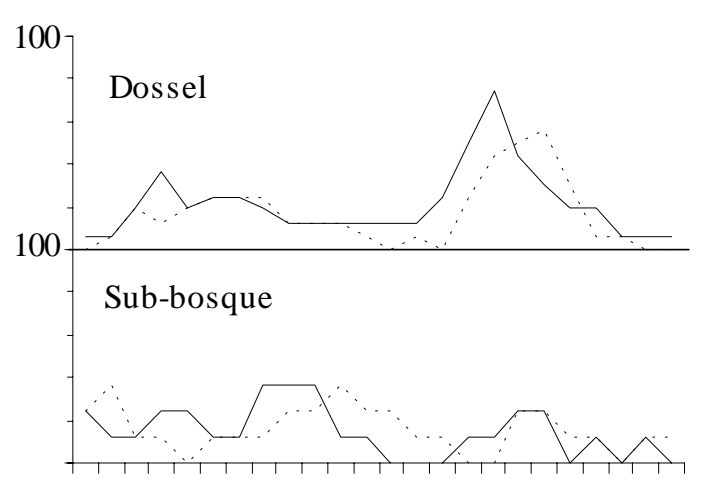

$\begin{array}{llllllllllll}\text { O } & \text { D } & \text { F } & \text { A } & \text { J } & \text { A } & \text { O } & \text { D } & \text { F } & \text { A } & \text { J } & \text { A }\end{array}$
Floresta inundável

A

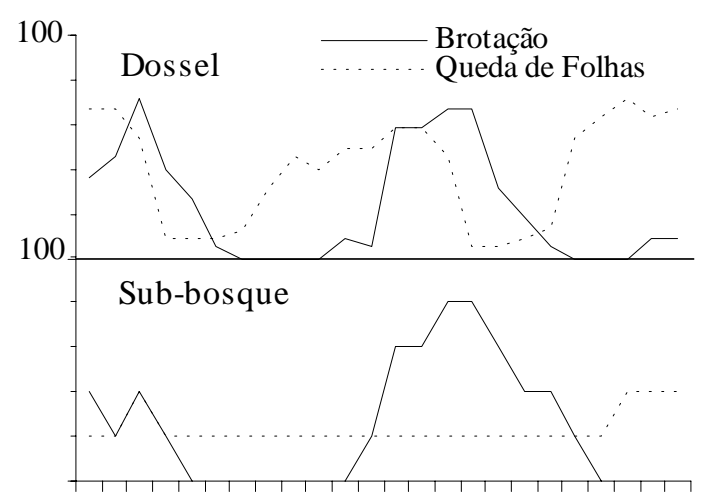

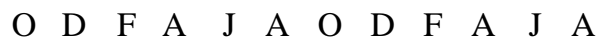

C

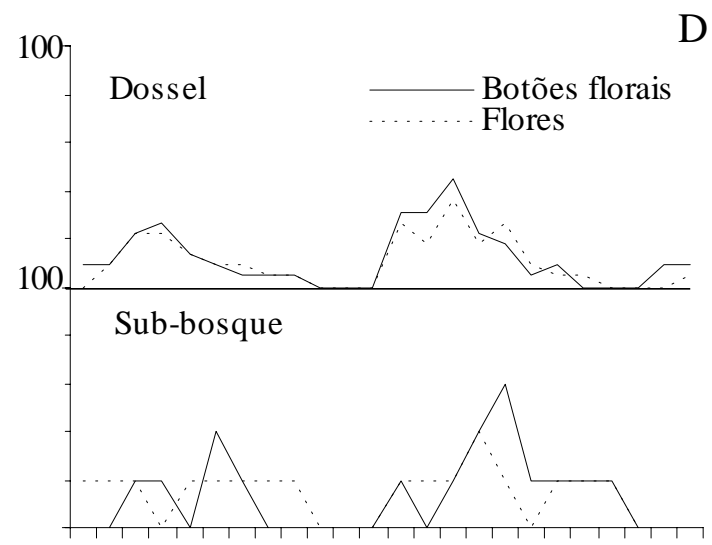

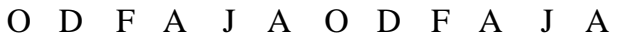

$\mathrm{E}$

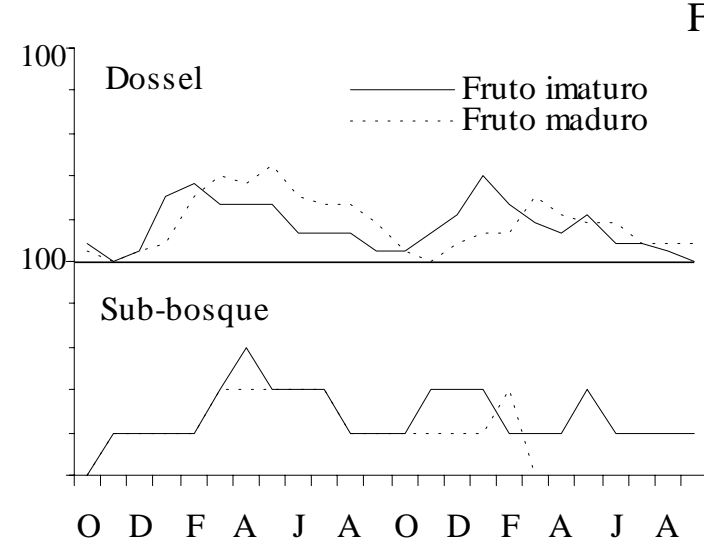

Mês

Figura 2. Mudança foliar (A, B), floração (C, D) e frutificação (E, F) em Floresta não inundável (29 espécies) e Floresta inundável (31 espécies), na Ilha do Mel, PR.

Figure 2. Leaf flushing and leaf fall (A, B), flowering (C, D) and fruiting (E, F) of Unflooded Forest (29 plant species) and Flooded Forest (31 plant species) in Ilha do Mel, Paraná State. 
Tabela 2. Correlações de Spearman $\left(r_{s}\right)$ entre as fenofases e as variáveis climáticas $(\mathrm{C}=$ comprimento do dia, $\mathrm{T}=$ temperatura média, $\mathrm{P}=$ precipitação), nas duas Florestas de Restinga da Ilha do Mel, PR. p<0,05. NS = não significativo. Entre parênteses, número de meses anteriores à observação (de 0 a 4 meses), em que a fenofase apresentou a maior correlação com a variável climática.

Table 2. Spearman's correlations $\left(r_{s}\right)$ among plant phenology and climatic variables $(\mathrm{C}=$ daylength, $\mathrm{T}=$ average temperature, $\mathrm{P}=$ rainfall), in two Sandy Coastal Forests in Ilha da Mel, Paraná State. $\mathrm{p}<0,05$. NS = non significant. ( ) number of months before the observation ( 0 to 4 months) that phenology shows the bigger correlation with the climatic variable.

\begin{tabular}{|c|c|c|c|c|c|c|c|}
\hline \multirow[t]{2}{*}{ Fenofase } & \multirow[t]{2}{*}{ Estrato } & \multicolumn{3}{|c|}{ Floresta não inundável } & \multicolumn{3}{|c|}{ Floresta inundável } \\
\hline & & $\mathrm{C}$ & $\mathrm{T}$ & $\mathrm{P}$ & $\mathrm{C}$ & $\mathrm{T}$ & $\mathrm{P}$ \\
\hline \multirow[t]{2}{*}{ Brotação } & Dossel & $0,87(0)$ & $-0,81(4)$ & $-0,74(4)$ & $0,92(0)$ & $-0,91(4)$ & $-0,84(4)$ \\
\hline & Sub-bosque & NS & NS & NS & $0,71(0)$ & $-0,66(4)$ & $-0,61(4)$ \\
\hline \multirow[t]{2}{*}{ Queda de folhas } & Dossel & $-0,61(3)$ & $-0,56(2)$ & $-0,51(1)$ & $-0,79(2)$ & $-0,78(1)$ & $-0,74(1)$ \\
\hline & Sub-bosque & $-0,76(1)$ & $-0,72(0)$ & $-0,60(0)$ & $-0,52(2)$ & $-0,55(1)$ & $-0,52(1)$ \\
\hline \multirow[t]{2}{*}{ Botões florais } & Dossel & $-0,63(4)$ & $-0,77(4)$ & $-0,65(4)$ & $0,84(0)$ & $-0,76(4)$ & $-0,72(4)$ \\
\hline & Sub-bosque & $0,50(1)$ & $0,47(0)$ & $0,41(0)$ & $0,68(2)$ & $0,66(1)$ & $0,67(1)$ \\
\hline \multirow[t]{2}{*}{ Flores } & Dossel & $0,81(1)$ & $-0,72(4)$ & $-0,65(4)$ & $0,84(1)$ & $0,80(0)$ & $0,71(0)$ \\
\hline & Sub-bosque & $0,46(2)$ & $0,42(1)$ & $0,41(0)$ & $0,52(1)$ & $0,48(0)$ & $0,47(1)$ \\
\hline \multirow[t]{2}{*}{ Frutos imaturos } & Dossel & $0,84(2)$ & $0,83(1)$ & $0,79(1)$ & $0,80(2)$ & $0,78(1)$ & $0,75(1)$ \\
\hline & Sub-bosque & NS & NS & NS & $0,43(4)$ & $0,45(3)$ & $0,44(2)$ \\
\hline \multirow[t]{2}{*}{ Frutos maduros } & Dossel & $0,85(3)$ & $0,84(2)$ & $0,80(2)$ & $0,81(4)$ & $0,78(3)$ & $0,71(3)$ \\
\hline & Sub-bosque & $-0,43(2)$ & NS & $-0,43(0)$ & NS & NS & NS \\
\hline Meses de atraso & (média \pm s.d) & $1,9 \pm 1,2$ & $2,0 \pm 1,6$ & $1,6 \pm 1,7$ & $1,6 \pm 1,4$ & $2,0 \pm 1,6$ & $1,6 \pm 1,4$ \\
\hline
\end{tabular}

(figura 2). Os padrões do dossel e do sub-bosque somente foram semelhantes com relação à brotação (FI: $\left.r_{s}=0,76, \mathrm{p}<0,01\right)$, queda de folhas (FI: $r_{s}=0,52$, $\mathrm{p}=0,01$ ), floração (FNI: $r_{s}=0,47, \mathrm{p}=0,02 ; \mathrm{FI}: r_{s}=0,50$, $\mathrm{p}=0,01)$ e frutos imaturos (FI: $r_{s}=0,47, \mathrm{p}=0,02$ ), mas diferiram nas demais situações.

\section{Discussão}

Padrões fenológicos gerais e o clima - O estudo mostrou que as Florestas de Restinga da Ilha do Mel apresentaram uma forte periodicidade na ocorrência das fenofases, embora a sazonalidade climática local seja pouco pronunciada. Tal periodicidade fenológica pode ser interpretada como uma resposta às variações no fotoperíodo e temperatura durante o ano, uma vez que houve uma forte relação da maior parte das fenofases com estes dois fatores, mas uma relação fraca com precipitação. Fenologia de plantas de regiões tropicais tem sido freqüentemente relacionada com clima (Wright
\& Van Schaik 1994), mas em locais onde não há restrição hídrica durante o ano, o comprimento do dia e a temperatura parecem ser mais importantes (Morellato et al. 2000, Marques et al. 2004). Estes dois fatores são tão fortemente relacionados que é impossível separar o efeito de cada um e na região ecotonal tropicalsubtropical (na qual a Ilha do Mel está incluída), as relações da fenologia das plantas com fotoperíodo e temperatura parecem ser mais fortes que na faixa tipicamente tropical (Marques et al. 2004).

A renovação de folhas no dossel das florestas da Ilha do Mel foi um evento sazonal, com queda concentrada entre os meses de outubro e dezembro e brotação imediatamente após, entre novembro e janeiro, ambas no início do período superúmido. Existem evidências de que o desencadeamento da queda de folhas e a brotação de espécies tropicais sejam relacionados a mudanças no fotoperíodo (Wright \& Van Schaik 1994) ou no estado hídrico da planta (Alvim 1964, Reich \& Borchert 1984). No entanto, na Ilha do Mel, 
onde não há restrições hídricas, o primeiro parece ser mais importante, pois a queda de folhas relacionou-se negativamente com comprimento do dia e temperatura (ambos 1 a 3 meses anteriores) enquanto a brotação mostrou relações positivas mais altas com comprimento do dia.

O padrão de mudança foliar verificado na Ilha do Mel no qual a brotação coincidiu com a época em que os dias são mais longos, pode, segundo Van Schaik et al. (1993) ser positivo uma vez que, na ausência de limitação hídrica, a fotossíntese é otimizada neste período de expansão foliar. Já a marcada sazonalidade na queda de folhas no final do período úmido e início do superúmido na Ilha do Mel, padrão pouco usual para florestas tropicais em geral (Frankie et al. 1974, Morellato et al. 1989), parece favorecer outros processos que ocorrem na floresta. Segundo Jordan (1985), em ambientes de baixa fertilidade do solo, como é o caso das formações da planície litorânea, uma economia de nutrientes poderia ser obtida através do aumento do tempo de retenção da folha, possibilitando a transferência de nutrientes diretamente para as folhas novas. Assim, é possível que as plantas das Florestas de Restinga retenham ao máximo suas folhas, atrasando a abscisão que passa a ocorrer na época mais úmida. Concomitante a isso, no período superúmido há também uma rápida decomposição e disponibilização de nutrientes no solo, pois a atividade de organismos decompositores e a umidade são maiores (Britez 1994).

O fato de nenhuma árvore estudada ser decídua, muito embora indivíduos de algumas espécies (Erythroxylum amplifolium, Guapira opposita, Psidium cattleianum) permaneçam, no período de queda, quase completamente sem folhas, reforça o caráter perenifólio das florestas da região atlântica. Nestas, a proporção de espécies decíduas é geralmente inferior a 10\% (Costa et al. 1997, Talora \& Morellato 2000, Morellato et al. 2000), aumentando para $12 \%$ na Floresta com Araucária (Marques et al. 2004) e para mais de $40 \%$ nas Florestas Estacionais Semideciduais (Morellato et al. 1989), o que sugere uma relação entre o grau de deciduidade nas florestas tropicais e a amplitude do período seco.

As comunidades florestais da Ilha do Mel mostraram sazonalidade também na produção de botões e flores, com pico junto com a brotação, entre novembro e dezembro, no início do período superúmido. Este resultado parece ser reflexo do aumento do fotoperíodo a partir de setembro, pois entre os fatores climáticos testados, este é o que a floração apresentou correlações mais elevadas. De fato vários estudos demonstraram que a concentração de espécies em flor no período de setembro a novembro nos neotrópicos está relacionada com o comprimento do dia (Ter Steege \& Persuad 1991, Rivera \& Borchert 2001, Morellato et al. 2000). A proximidade temporal entre a floração e a brotação sugere que seja energeticamente mais eficiente transferir recursos diretamente para um órgão em crescimento, que estocá-los para uma translocação posterior. Então, é previsível que o pico de floração coincida com o período de maior insolação e, consequientemente, com a emergência de folhas novas em locais onde não há limitação de água (Van Schaik et al. 1993). Logo após o estímulo do aumento do fotoperíodo para a produção de botões florais, a antese deve ter a influência dos outros fatores climáticos, pois as correlações desta última fenofase (flores) com temperatura e precipitação foram mais elevadas.

Logo após a floração do dossel, picos de frutos imaturos (em janeiro) e maduros (em março e abril), se sucederam nas duas florestas no final da estação superúmida e estiveram associados a maiores comprimento do dia, temperatura e precipitação dos 2-4 meses anteriores. Além do clima, é possível que os fatores seletivos que determinam a época de ocorrência da frutificação estejam também relacionados com outras fases do desenvolvimento da planta, como a germinação das sementes, que deve ocorrer num período propício para o estabelecimento das plântulas (Marques 2002). Comparação com outras florestas da região atlântica As Florestas de Restinga da Ilha do Mel apresentaram padrões fenológicos em geral semelhantes às demais formações atlânticas. No que se refere a árvores, produção de folhas no período mais chuvoso (Costa et al. 1997, Talora \& Morellato 2000, Morellato et al. 2000), queda de folhas no final do período úmido e início do superúmido (Jackson 1978, Delitti 1987, Costa et al. 1997, Morellato et al. 2000) e floração no início do período úmido (Costa et al. 1997, Talora \& Morellato 2000, Morellato et al. 2000), são padrões já encontrados e que se repetiram na Ilha do Mel. No entanto, frutificação concentrada no final da estação mais úmida na Ilha do Mel não é um padrão usual, pois normalmente distribuí-se ao longo do ano, com pico em dezembrofevereiro, na época mais úmida (Jackson 1981, Costa et al. 1997, Morellato et al. 2000).

Tais semelhanças fenológicas entre as Florestas de Restinga da Ilha do Mel e outros ecossistemas atlânticos é previsível, uma vez que aproximadamente $80 \%$ das espécies das Restingas são comuns ou se originaram na Floresta Atlântica (Araujo 2000). Portanto, mesmo localizando-se atualmente em situações 
edáfica e climaticamente distintas das pretéritas, as espécies das Restingas preservam grande parte de suas características fenológicas, funcionando de forma semelhante às demais formações atlânticas.

Semelhanças entre florestas - Diferenças ambientais entre a Floresta não inundável (FNI) e a Floresta inundável (FI), representadas principalmente pelos distintos níveis de saturação hídrica do solo, em geral não foram suficientes para determinar diferenças nos padrões fenológicos das duas comunidades. A semelhança fenológica entre as florestas foi notadamente verificada no dossel, em todas as fenofases (queda de folhas, brotação, floração e frutificação). Isto sugere que a fenologia para esta sinúsia seja fortemente influenciada pelo clima regional e pouco por fatores ambientais na escala local. Além disso, as duas florestas apresentam alguma similaridade florística $(S=0,49)$. Nas formações localizadas na planície litorânea é comum um mesmo conjunto de espécies aparentadas ocorrer em ambientes muito distintos, como a FNI e a FI. Como a fenologia tem um componente filogenético forte (Wright \& Calderon 1995), a sobreposição de padrões no dossel das duas florestas estudadas deve também estar refletindo esta semelhança florística.

As maiores diferenças nos padrões fenológicos entre as florestas estudadas, restringiram-se ao subbosque, principalmente na queda de folhas, floração e frutificação. No período de menor precipitação, enquanto espécies da FNI apresentaram folhas amareladas e em abscisão, na FI o sintoma mais visível era a murcha de folhas, principalmente nas ervas. Como na FNI o nível do lençol freático é mais profundo (Britez 1994), é possível que o solo apresente algum nível de deficiência hídrica superficial que é sentida principalmente pelas ervas e arbustos desta floresta, levando-as à queda foliar. Situação semelhante foi descrita por Opler et al. (1980) para o sub-bosque de duas florestas com extrema diferença nas condições hídricas do solo. Então, para plantas do sub-bosque, até mesmo pequenas variações na umidade do solo das duas florestas podem ser importantes para a ocorrência de determinadas fenofases. Além disso, as diferenças florísticas deste estrato entre as duas florestas $(S=0,21)$ também deve ter contribuído para tais diferenças.

Diferenças entre sinúsias - Nas duas florestas estudadas, os indivíduos do dossel apresentaram, em geral, maior sincronia entre si (existência de picos) que os do sub-bosque (ausência de picos). Com isso os eventos mudança foliar, floração e frutificação do dossel e do sub-bosque, raramente coincidiram dentro de uma mesma floresta. Estas diferenças podem, em parte, ser explicadas pelas características dos grupos de espécies de cada sinúsia. Enquanto o dossel compreende exclusivamente espécies arbóreas de médio a grande porte, muito semelhantes em suas necessidades de recursos, no sub-bosque, ervas (como as Bromeliaceae, Araceae, Cyperaceae, Poaceae, Piperaceae e Loganiaceae) e arbustos (como as Rubiaceae e Arecaceae) exploram o mesmo estrato da floresta, mas são muito pouco relacionados em morfologia, profundidade do sistema radicial, etc. Como plantas de diferentes formas de vida tendem a apresentar padrões fenológicos distintos (Marques et al. 2004), é de se esperar que espécies do sub-bosque não sobreponham sua fenologia entre si e muito menos se assemelhem aos padrões do dossel.

Este contraste entre a sazonalidade do dossel e o ritmo descontínuo do sub-bosque, principalmente nas fenofases floração e frutificação pode, por sua vez, ter papel importante para a manutenção de populações de animais polinizadores e dispersores pois, a qualquer momento do ano, há espécies em flor e fruto (Opler et al. 1980)

Agradecimentos - A Fabio R. Scarano, Flavio A.M. dos Santos, James Roper, José Eugênio C. Figueira, Ivan Schiavini, Ivany Válio, Marcelo Tabarelli e Ricardo Ribeiro Rodrigues, pelas sugestões à primeira versão do manuscrito; aos Programa de Auxílio à Pesquisa da Universidade Federal do Paraná e Programa de Pós-graduação em Biologia Vegetal da Universidade Estadual de Campinas, pelo financiamento de parte do projeto e ao Instituto Ambiental do Paraná (IAP) pela permissão em trabalhar na Estação Ecológica da Ilha do Mel. M.C.M. Marques agradece à Capes, pela concessão da bolsa PICDT; Ricardo Miranda de Britez, Yasmin Grummt Naddaf e Luciana Romanó pelo auxílio em campo.

\section{Referências bibliográficas}

ALVIM, P.T. 1964. Periodicidade do crescimento das árvores em climas tropicais. In Anais do XV Congresso Nacional de Botânica (Sociedade Botânica do Brasil, ed.), Sociedade Botânica do Brasil, Porto Alegre, p.405-422.

ARAUJO, D.S.D. 2000. Análise florística e fitogeográfica das Restingas do Estado do Rio de Janeiro. Tese de doutorado (Ecologia), Universidade Federal do Rio de Janeiro, Rio de Janeiro.

ARROYO, M.T.K., ARMESTO, J.J. \& VILLAGRÁN, C. 1981. Plant phenological patterns in the high Andean cordillera of central Chile. Journal of Ecology 69:205-223.

BRITEZ, R.M. 1994. Ciclagem de nutrientes minerais em duas florestas da Planície Litorânea da Ilha do Mel, Paranaguá, PR. Dissertação de mestrado (Ciências do solo), Universidade Federal do Paraná, Curitiba. 
BRITEZ, R.M., SANTOS-FILHO, A., REISSMANN, C.B., SILVA, S.M., ATHAYDE, S.F., LIMA, R.X. \& QUADROS, R.M.B. 1997. Nutrientes do solo de duas florestas da Planície Litorânea da Ilha do Mel, Paranaguá, PR. Revista Brasileira de Ciências do Solo 21:625-634.

CALLADO, C.H., SILVA NETO, S.J., SCARANO, F.R. \& COSTA, C.G. 2001. Periodicity of growth rings in some flood-prone trees of the Atlantic Rain Forest in Rio de Janeiro, Brazil. Trees 15:492-497.

COSTA, M.L.M.N., ANDRADE, A.C.S. \& PEREIRA, T.S. 1997. Fenologia de espécies arbóreas em Floresta Montana na Reserva Ecológica de Macaé de Cima. In Serra de Macaé de Cima: Diversidade florística e conservação em Mata Atlântica (H.C. Lima \& R.R. Guedes-Bruni, eds.). Jardim Botânico do Rio de Janeiro, Rio de Janeiro, p.169-186.

CROAT, T.B. 1975. Phenological behavior of habit and habitat classes on Barro Colorado Island (Panama Canal Zone). Biotropica 7:270-277.

DELITTI, W.B.C. 1987. Produção de folhedo na Mata Pluvial Tropical da Estação Ecológica da Juréia, SP. Ciência e Cultura 39:600-601.

FERNANDES, A. 2000. Fitogeografia brasileira. Multigraf, Fortaleza.

FOURNIER, L.A. \& CHARPANTIER, C. 1975. El tamaño de la muestra y la frecuencia de las observaciones en el estudio de las características fenológicas de los árboles tropicales. Turrialba 25:45-48.

FRANKIE, G.W., BAKER, H.G. \& OPLER, P.A. 1974. Comparative phenological studies of trees in tropical wet and dry forests in the lowlands of Costa Rica. Journal of Ecology 62:881-913.

HILTY, S.L. 1980. Flowering and fruiting periodicity in a Premontane Rain Forest in Pacific Colombia. Biotropica 12:292-306.

JACKSON, J.F. 1978. Seasonality of flowering and leaf-fall in a Brazilian Subtropical Lower Montane Moist Forest. Biotropica 10:38-42.

JACKSON, J.F. 1981. Seed size as a correlate of temporal and spatial patterns of seed fall in a Neotropical Forest. Biotropica 13:121-130.

JORDAN, C.F. 1985. Nutrient cycling in tropical ecosystems. Wiley \& Sons, New York.

KUBITZKI, K. \& ZIBURSKI, A. 1994. Seed dispersal in flood plain forests of Amazonia. Biotropica 26:30-43

LONGMAN, K.A. \& JENÍK, J. 1987. Tropical forest and its environment. Longman Scient. \& Tech, New York.

MARQUES, M.C.M. 2002. Dinâmica da dispersão de sementes e regeneração de plantas da Planície Litorânea da Ilha do Mel, PR. Tese de doutorado (Biologia Vegetal), Universidade Estadual de Campinas, Campinas.

MARQUES, M.C.M., ROPER, J.J \& SALVALAGGIO, A.P.B. 2004. Phenological patterns among plant life forms in a Subtropical Forest in Southern Brazil. Plant Ecology 173:203-213.
MORELLATO, L.P.C., RODRIGUES, R.R., LEITÃO FILHO, H.F. \& JOLY, C.A. 1989. Estudo comparativo de espécies arbóreas de Floresta de Altitude e Floresta Mesófila Semidecídua na Serra do Japi, Jundiaí, São Paulo. Revista Brasileira de Botânica 12:85-98.

MORELLATO, L.P.C., TALORA, D.C., TAKAHASI, A., BENCKE, C.C., ROMERA, E.C. \&ZIPPARRO, V.B. 2000. Phenology of Atlantic Rain Forest trees: a comparative study. Biotropica 32:811-823.

NEGRELLE, R.R.B. 2002. The Atlantic Forest in Volta Velha Reserve: a tropical rain forest site outside the tropics. Biodiversity and Conservation 11:887-919.

OPLER, P.A., FRANKIE, G.W. \& BAKER, H.G. 1980. Comparative phenological studies of treelet and shrub species in tropical wet and dry forests in the lowlands of Costa Rica. Journal of Ecology 68:167-188.

REICH, P.B. \& BORCHERT, R. 1984. Water stress and tree phenology in a tropical dry forest in the lowlands of Costa Rica. Journal of Ecology 72:61-74.

RIVERA, G. \& BORCHERT, R. 2001. Induction of flowering in tropical trees by a $30-$ min reduction in photoperiod: evidence from field observations and herbarium specimens. Tree Physiology 21:201-212.

SILVA, S. 1998. As formações vegetais da Planície Litorânea da Ilha do Mel, Paranaguá-PR, principais características florísticas e estruturais. Tese de doutorado (Biologia Vegetal), Universidade Estadual de Campinas, Campinas.

SILVA, S.M., BRITEZ, R.M., SOUZA, W.S. \& JOLY, C.A. 1994. Fitossociologia do componente arbóreo da Floresta de Restinga da Ilha do Mel, Paranaguá, PR. In Anais do $3^{\circ}$ Simpósio sobre Ecossistemas da Costa Brasileira (S. Watanabe, coord.). Aciesp, São Paulo, v.3, p.33-48.

SMITHE, N. 1970. Relationships between fruiting seasons and seed dispersal methods in a neotropical forest. The American Naturalist 104:25-35.

TALORA, D.C. \& MORELLATO, L.P.C. 2000. Fenologia de espécies arbóreas em floresta de planície litorânea do sudeste do Brasil. Revista Brasileira de Botânica 23:13-26.

TER STEEGE, H. \& PERSAUD, C.A. 1991. The phenology of Guyanese timber species: a compilation of a century of observations. Vegetatio 95:177-198.

VAN SCHAIK, C.P., TERBORGH, J.W. \& WRIGHT, S.J. 1993. The phenology of tropical forests: adaptative significance and consequences for primary consumers. Annual Review of Ecology and Systematics 24:353-377.

WRIGHT, S.J. \& CALDERON, O. 1995. Phylogenetic patterns among tropical flowering phenologies. Journal of Ecology 83:937-948.

WRIGHT, S.J. \& VAN SCHAIK, C.P. 1994. Light and the phenology of tropical trees. The American Naturalist 143:193-199.

ZAR, J.H. 1999. Biostatistical analysis. Prentice-Hall, New Jersey. 